\title{
Longitudinal clinical observation of 4 patients with preclinical stage of idiopathic normal pressure hydrocephalus
}

\author{
Shingo Azuma*, Takashi Suehiro, Hiroaki Kazui, Shunsuke Sato, Yukiko Suzuki, Hideki Kanemoto, Kenji Yoshiyama \\ From Hydrocephalus 2015 \\ Banff, Canada. 18-21 September 2015
}

\section{Introduction}

In patients with idiopathic normal pressure hydrocephalus (iNPH) with features of Disproportionately Enlarged Subarachnoid-space Hydrocephalus (DESH), ventriculomegaly and the tight high-convexity and medial subarachnoid spaces appear in magnetic resonance (MR) images before the occurrence of objective symptoms. There are few reports of longitudinal observation of clinical course in DESH-type iNPH patients with no objective symptom.

\section{Methods}

We longitudinally observed 4 patients ( 1 female and 3 males with a mean age of 73.8 years) with features of DESH who visited the neuropsychological clinic in our hospital, whose symptoms were not apparent in the first visit. We evaluated the triad symptoms with iNPHGS and conducted the cognitive and gait examinations once a year. We also evaluated quantitative rCBF of those patients by 123I-IMP single photon emission computed tomography (SPECT) using the autoradiography (ARG) method.

\section{Results}

Based on the scores of iNPHGS, we classified 4 patients into two groups; two stable patients and two deteriorated patients. In one patient of the stable group, the score of the Mini-mental State Examination (MMSE) did not change and the score of the Frontal Assessment Battery (FAB) and the Timed Up \& Go Test (TUG) improved, however, in the other patient, the score of MMSE, FAB and TUG worsened. In the deteriorated group, one patient expressed the gait disturbance and the other patient did the gate disturbance and the cognitive impairment. In the

\footnotetext{
* Correspondence: shingo.azuma.328@gmail.com
}

Osaka University Graduate School of Medicine, Japan former patient, the score of MMSE and FAB worsened and a wide-based gate and the disturbance of the dynamic equilibrium appeared, although the score of TUG did not change. In the latter patient, the score of FAB and TUG worsened but the score of MMSE did not change. The changes of quantitative $\mathrm{rCBF}$ of 4 patients were various.

\section{Conclusions}

The different clinical courses and changes of quantitative $\mathrm{rCBF}$ were observed in each patient.

Published: 18 September 2015

doi:10.1186/2045-8118-12-S1-P4

Cite this article as: Azuma et al:: Longitudinal clinical observation of 4 patients with preclinical stage of idiopathic normal pressure hydrocephalus. Fluids and Barriers of the CNS 2015 12(Suppl 1):P4.

\section{Submit your next manuscript to BioMed Central and take full advantage of: \\ - Convenient online submission \\ - Thorough peer review \\ - No space constraints or color figure charges \\ - Immediate publication on acceptance \\ - Inclusion in PubMed, CAS, Scopus and Google Scholar \\ - Research which is freely available for redistribution \\ Submit your manuscript at www.biomedcentral.com/submit}

